\title{
Continuous in vivo Monitoring of Blood Diffusible Calcium Using On-line Microdialysis Sampling Coupled with Flame Atomic Absorption Spectrometry
}

\author{
Wei-Chang Tseng,* Yuh-Chang Sun,** Cheng-Fa LeE,*** Mo-Hsiung YAng,** \\ and Yeou-Lih HuAnG***† \\ *Department of Medical Technology, Fooyin University, Kaohsiung, Taiwan \\ **Department of Nuclear Science, National Tsing-Hua University, Hsinchu, Taiwan \\ ***Faculty of Biomedical Laboratory Science, Kaohsiung Medical University, Kaohsiung, Taiwan
}

\begin{abstract}
A direct, rapid and continuous in vivo monitoring of diffusible calcium in the blood of living rabbits has been developed using microdialysis sampling coupled on-line with flame atomic absorption spectrometry. Microdialysates perfused through implanted microdialysis probes were collected with a sample loop on an injection valve and directly introduced into the flame atomizer by a carrier solution. An ultrapure saline solution $(0.9 \% \mathrm{NaCl}, \mathrm{pH} 7.2)$ was used as the perfusion solution at a flow rate of $20 \mu \mathrm{min}^{-1}$ via the microdialysis probe. A $0.1 \% \mathrm{La}$ solution in $0.5 \% \mathrm{HNO}_{3}$ solution was employed as the carrier solution at a nebulizer uptake flow rate of $2.5 \mathrm{ml} \mathrm{min}{ }^{-1}$. The interval for each determination was $2.5 \mathrm{~min}$ ( $2 \mathrm{~min}$ of sampling time, $20 \mathrm{~s}$ of read time and $10 \mathrm{~s}$ of washing time). The performance characteristics of the online microdialysis-FAAS system were validated as follows: linearity range, $0-100 \mathrm{mg} \mathrm{l}^{-1}$; detection limit $(3 \sigma, n=7)$, $3.66 \mathrm{mg} \mathrm{l}^{-1}$; precision (RSD, $n=50$ ), 6.2\%. For the evaluation of analytical accuracy, the proposed on-line method was compared with the in vivo no net flux method. The use of an on-line microdialysis-FAAS system permitted the in situ, dynamic and continuous in vivo monitoring of diffusible calcium in the blood of the living rabbits after $\mathrm{CaCl}_{2}$ administration with a temporal resolution of $2.5 \mathrm{~min}$.
\end{abstract}

(Received August 12, 2004; Accepted October 27, 2004)

\section{Introduction}

In the blood, calcium $(\mathrm{Ca})$ exists in protein-bound, complexbound, and ionized fractions. Ionized $\mathrm{Ca}$ is the biologicallyactive portion of $\mathrm{Ca}$ and is not bound to proteins in the blood. Ionized $\mathrm{Ca}$ concentration of extracellular fluid is tightly regulated to maintain cell membrane integrity, blood coagulation, hormone metabolism, and neuromuscular transmission. ${ }^{1}$ Small decreases in ionized calcium can cause paresthesia and seizures; in contrast, increases in ionized calcium lead to constipation, obtundation, and coma. Diffusible Ca, consisting of a complex-bound and a free ionized fraction, is also considered as a physiologically active species and may play roles in calcium homeostasis. ${ }^{2}$ Although the predominant biological activity of calcium is attributed to its ionized fraction, any change of diffusible calcium would also result in diseases. ${ }^{3}$ Thus, to measure diffusible calcium for clinical diagnosis is of crucial importance.

Usually ionized $\mathrm{Ca}$ analysis is carried out by potentiometry or fluorometry; however, expensive and specialized electrodes and costly reagents are needed. ${ }^{4,5}$ In a clinical laboratory, among the techniques available for the determination of ionized calcium in complex biological fluids, ion-selective electrode (ISE) sensors are commonly used because of its sensitivity and selectivity. However, on-line in vivo continuous Ca measurement using ISE

$\dagger$ To whom correspondence should be addressed.

E-mail: yelihu@kmu.edu.tw is still not available. Small changes in ionized blood $\mathrm{Ca}$ concentration can have lethal consequences. Thus, on-line continuous monitoring of ionized blood $\mathrm{Ca}$ concentration is of utmost importance for the effective management of patients with unstable electrolyte status in the body fluids. For these reasons, there is a growing interest in designing and developing various types of on-line techniques for rapid, easy, and reliable analysis of Ca concentration in blood. ${ }^{2,7}$

Microdialysis, ${ }^{8-11}$ a powerful sampling technique used to obtain protein-free samples, has become an important technique for continuous in vivo sampling of the extracellular fluid in discrete compartments of living systems. A microdialysis system is easy to automate and can be on-line coupled with many analytical techniques, such as liquid chromatography, ${ }^{12}$ capillary electrophoresis, ${ }^{13}$ mass spectrometry, ${ }^{14}$ flow-injection analysis, ${ }^{15-18}$ and electrochemical detection. ${ }^{19}$ In addition, online microdialysis sampling can prevent analyte degradation during sample preparation. This is an advantage since ionized blood calcium concentration is easily affected by exposure to oxygen and $\mathrm{pH}^{20}$ Recently, in vivo monitoring of $\mathrm{Ca}$ in blood was documented using a flow-injection on-line microdialysis system coupled with fluorescent detection. ${ }^{2}$

As is well known, the three major atomization methods for atomic absorption spectrometry (AAS) are flame, electrothermal, and hydride generation techniques. In our previous studies, two hyphenated techniques of on-line microdialysis sampling coupled to hydride generation atomic absorption spectrometry ${ }^{21}$ and electrothermal atomic absorption spectrometry $^{22}$ have been developed for in vivo monitoring of 
arsenic and manganese in living animals. Flame AAS (FAAS) is one of the most popular techniques for metal determination; however, the high sample volume needed would limit its on-line analysis. To our knowledge, no studies have been made to investigate the technique of on-line microdialysis coupled with FAAS for the determination of diffusible metals in biological fluids with complex matrices. The aim of this study was to develop a method of microdialysis sampling coupled on-line with FAAS for the continuous in vivo monitoring of diffusible $\mathrm{Ca}$ in the blood of living rabbits. In the present work, operating conditions and analytical performance of the proposed on-line microdialysis-FAAS system were optimized and validated. The proposed method was applied successfully to determine the nearly real-time concentration of diffusible $\mathrm{Ca}$ in the blood of rabbits calcium chloride $\left(\mathrm{CaCl}_{2}\right)$ had been administrated.

\section{Experimental}

Reagents and vessels

High-purity water $(18.3 \mathrm{M} \Omega \mathrm{cm})$ was prepared with a deionized water system (Milli-Q, Millipore) and used throughout this work. All of the reagents used were of the highest available purity and were at least of analytical grade. The perfusion solution was prepared by dissolving $0.9 \mathrm{~g}$ of $\mathrm{NaCl}$ (Merck, ultrapure grade) in $100 \mathrm{ml}$ of high-purity water and the $\mathrm{pH}$ was adjusted to 7.2. The carrier solution was prepared by dissolving lanthanum oxide $\left(\mathrm{LaO}_{3}\right.$, Merck, ultrapure grade) in $1000 \mathrm{ml}$ of $0.5 \% \mathrm{HNO}_{3}$. Stock solutions (1000 $\left.\mathrm{mg}^{-1}\right)$ of $\mathrm{Ca}$ were purchased from Merck. The working aqueous $\mathrm{Ca}$ standard solutions were diluted fresh daily with $0.9 \% \mathrm{NaCl}$.

Before each use, all containers and pipette tips were scrubbed in $20 \%$ nitric acid (Riedel-de Haën, Germany) overnight, then cleaned with high-purity water five times. The tubings used for the connections of all apparatuses were perfused with highpurity water to flush out contamination. In order to avoid contamination of $\mathrm{Ca}$, metal-free syringes $(10 \mathrm{ml}$ Luer Tip syringe, mode 81601, Hamilton, USA) were used as the perfusion syringes throughout this work. Twenty millimeters of polyetheretherketon (PEEK) tubing $(0.25 \mathrm{~mm}$ i.d.) was fitted to the syringe, making a homemade metal-free needle.

\section{Instrumentation}

A schematic diagram of the on-line microdialyis-FAAS system for the continuous determination of diffusible $\mathrm{Ca}$ in the blood of living rabbits is shown in Fig. 1. Microdialysates perfused through a microdialysis probe were collected in a sample loop on a six-port on-line injection valve for direct injection into a flame atomizer by a nebulizer uptake flow. A personal computer was used to operate the spectrometer and to acquire the atomic absorption signal.

The microdialysis system was purchased from Carnegie Medicine Associates (CMA, Stockholm, Sweden). The microdialysis sampling system consists of a microinjection syringe pump (CMA/100) and a $24 \mathrm{~mm}$-long microdialysis probe $(\mathrm{CMA} / 20)$ with a $10 \mathrm{~mm}$-long and a $0.5 \mathrm{~mm}$-diameter polycarbonate membrane, which is metal-free and has a molecular mass cut-off of $20 \mathrm{kDa}$. Fluorinated ethylene polypropylene $(\mathrm{FEP})$ tubing $(50 \mathrm{~cm}$ long $\times 0.12 \mathrm{~mm}$ i.d.; internal volume of $1.2 \mu \mathrm{l}$ per $100 \mathrm{~mm}$ length; CMA, Stockholm, Sweden) was used to connect the microinjection syringe pump to the inlet of the probe and the outlet of the probe to the sample loop. The total dead volume of FEP tubing from probe to sample loop was approximately $6 \mu$ l. All connections of FEP

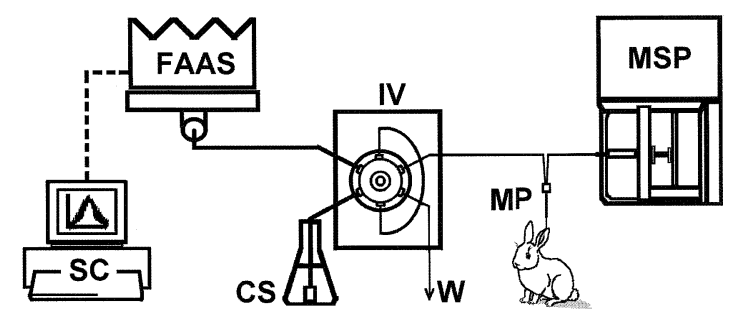

Fig. 1 Schematic diagram of the on-line microdialysis-FAAS system for continuous determination of diffusible $\mathrm{Ca}$ in the blood of living rabbits. MSP, microinjection syringe pump; MP, microdialysis probe; IV, injection valve; W, waste; CS, carrier solution; FAAS, flame atomic absorption spectrometer; $\mathrm{SC}$, spectrometer computer.

tubing to the microinjection syringes, the probe and the other FEP tubing were accomplished by tubing adaptors (CMA, Stockholm, Sweden), which ensure tight, zero internal volume connections.

The on-line interface was performed with a six-port on-line injection valve (Omnifit smart actuator, Cambridge, UK). The on-line injection valve has an inert metal-free Teflon body designed for avoiding the contamination of metals. The connections and conduits were made of polytetrafluoroethylene (PTFE) connecting tubes $(11 \mathrm{~cm}$ long $\times 1.0 \mathrm{~mm}$ i.d.; PerkinElmer B019-1058). A $20 \mathrm{~cm}$-long delivery tube was used to connect the injection valve with a flame atomizer. An atomic absorption spectrometer (Perkin-Elmer Model 5100 PC) was used. The system was operated through a personal computer and the associated AA WinLab $b_{\text {Tm }}$ software, version 2.0. Peak area (integrated absorbance); statistical data were printed out using a laser printer.

\section{Procedures}

To characterize the on-line microdialysis-FAAS system, we introduced the microdialysate sample directly into the injection valve in a continuous manner. Aqueous $\mathrm{Ca}$ standards were used to estimate the operational parameters (perfusion flow rate, sampling time, nebulizer uptake rate and detection time).

The linearity of the calibration curve was evaluated from 0 to $200 \mathrm{mg}^{-1}$ by the on-line microdialysis-FAAS system. Calculation of the detection limit $(3 \sigma)$ was carried out by 7 measurements of baseline noise. To test long-term stability and precision of the method proposed, we inserted the microdialysis probe into the left-ear vein of rabbits, after which on-line sampling and detection was conducted every $2.5 \mathrm{~min}$ for 125 min (50 continuous measurements). The accuracy was checked by implanting the probe in the left-ear vein of three rabbits, the results of which were compared with the in vivo no net flux (NNF) method as described previously. ${ }^{2,23,24}$ In the in vivo $\mathrm{NNF}$ method, the microdialysis sampling was performed by perfusing the probe with different concentrations of $\mathrm{Ca}$ standard solution $\left(10,20,40,60\right.$ and $\left.80 \mathrm{mg} \mathrm{l}^{-1}\right)$ at a flow rate of $2 \mu 1 \mathrm{~min}^{-1}$. For every change of $\mathrm{Ca}$ concentration, the first dialysate was discarded to avoid the residual effect of the previous measurement.

Adult male New Zealand White rabbits (2500 - 3000 g) were obtained from the Livestock Research Institute of the Republic of China (Tainan, Taiwan). These animals were specifically pathogen-free and were allowed to acclimate to their environmentally controlled quarters $\left(25^{\circ} \mathrm{C}\right.$ and $12: 12 \mathrm{~h}$ lightdark cycle) for at least 5 days and then fasted overnight prior to the day of experimentation. The rabbits were initially anesthetized with an anaesthetic solution (ketamine $45 \mathrm{mg} \mathrm{kg}^{-1}$, 
Table 1 Optimized operating conditions of the on-line microdialysis-FAAS system for continuous monitoring of blood diffusible $\mathrm{Ca}$

\begin{tabular}{|c|c|}
\hline \multicolumn{2}{|l|}{ Microdialysis sampling } \\
\hline Probe (CMA/20) & $\begin{array}{l}10 \times 0.5 \mathrm{~mm} \text { membrane, metal-free } \\
\text { and cut off at } 20 \mathrm{kDa}\end{array}$ \\
\hline Perfusion solution & Saline $(0.9 \% \mathrm{NaCl})$ solution $(\mathrm{pH} 7.2)$ \\
\hline Perfusion flow rate & $20 \mu 1 \mathrm{~min}^{-1}$ \\
\hline Sampling time & $2 \min$ \\
\hline \multicolumn{2}{|l|}{ On-line interface } \\
\hline Carrier solution & $0.1 \% \mathrm{La}$ in $0.5 \% \mathrm{HNO}_{3}$ \\
\hline Nebulizer uptake rate & $2.5 \mathrm{ml} \mathrm{min}^{-1}$ \\
\hline \multicolumn{2}{|l|}{ FAAS system } \\
\hline Lamp type & Calcium hollow cathode lamp \\
\hline Wavelength & $422.7 \mathrm{~nm}$ \\
\hline Slit width & Low $0.7 \mathrm{~nm}$ \\
\hline Lamp current & $10 \mathrm{~mA}$ \\
\hline Oxidant & $\operatorname{Air}\left(10 \mathrm{~L} \mathrm{~min}^{-1}\right)$ \\
\hline Fuel & Acetylene $\left(3.8 \mathrm{~L} \mathrm{~min}^{-1}\right)$ \\
\hline Signal type & Peak area (integrated absorbance) \\
\hline Read time & $20 \mathrm{~s}$ \\
\hline Washing time & $10 \mathrm{~s}$ \\
\hline
\end{tabular}

xylazine $5 \mathrm{mg} \mathrm{kg}^{-1}$ and atropine $0.1 \mathrm{mg} \mathrm{kg}^{-1}$ body weight), and continued to be anesthetized with pentobarbital $\left(10 \mathrm{mg} \mathrm{kg}^{-1} \mathrm{~h}^{-1}\right)$ throughout the experimental period. The microdialysis probe (CMA/20, $10 \mathrm{~mm}$ dialysis membrane) was implanted into the left-ear vein of rabbit. The probe was perfused with a saline solution containing anticoagulant (20 IU ml-1 of heparin). The microdialysates collected over the first $2 \mathrm{~h}$ were discarded to prevent acute adverse effects on the animals from the surgical procedures. The probe was connected to the on-line analytical system approximately $2 \mathrm{~h}$ after surgery. Ca level was continuously monitored by the proposed on-line system every $2.5 \mathrm{~min}$. Basal Ca levels were monitored for at least $17.5 \mathrm{~min}$ prior to $\mathrm{Ca}$ administration. When the seventh measurement was completed, $\mathrm{CaCl}_{2}$ (20 mg kg-1 body weight) was injected into the right-ear vein of the rabbit and the $\mathrm{Ca}$ was continuously monitored every $2.5 \mathrm{~min}$ for approximately $100 \mathrm{~min}$.

\section{Results and Discussion}

Optimization of the on-line microdialysis-FAAS system

The optimized operating conditions of the on-line microdialysis-FAAS system for determining of diffusible $\mathrm{Ca}$ are summarized in Table 1. Instead of off-line transporting the microdialysate to the FAAS, an injection valve was employed as an on-line interface. The manifold of the on-line microdialysis coupled with FAAS is shown schematically in Fig. 1. In this system design, an on-line injection valve converted the continuous sampling stream of the microdialysis system into discrete samples. In the loading step, the perfusion flow rate of $20 \mu 1 \mathrm{~min}^{-1}$ was converted into a $40 \mu \mathrm{l}$ sample by the injection valve. After a 2 min loading period, the injection valve was switched to the injection position. The microdialysate sample trapped in the loop was injected into delivery tubing at timed intervals. In the injection step, the $0.1 \%$ La carrier solution was introduced into the sample loop to propel the microdialysate sample into the flame atomizer at a nebulizer uptake flow rate of $2.5 \mathrm{ml} \mathrm{min}{ }^{-1}$. Meanwhile, the spectrometer computer was actuated to read the atomic absorption signal for $20 \mathrm{~s}$. To avoid the residual effect of the

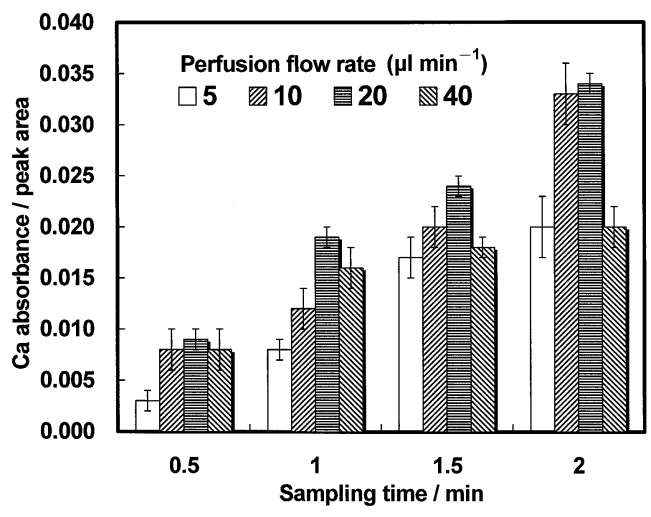

Fig. 2 Effect of perfusion flow rate and sampling time on the absorbance of $30 \mathrm{mg} \mathrm{l}^{-1} \mathrm{Ca}$ standard solution using on-line microdialysis-FAAS system. The nebulizer uptake rate and the read time of FAAS were set at $5 \mathrm{ml} \mathrm{min} \mathrm{m}^{-1}$ and $10 \mathrm{~s}$, respectively. The other conditions are as in Table 1. The error bars represent standard deviations $(n=3)$.

previous sample, the sample loop was washed by carrier solution for $10 \mathrm{~s}$ prior to the next loading step. The detailed observations are described as follows.

In the present work, a commercial metal-free probe (CMA/20) incorporating a relatively long microdialysis membrane of 10 $\mathrm{mm}$ was used to permit rapid and continuous sampling. In order to reduce the complexity of the matrix and to avoid $\mathrm{Ca}$ contamination, we perfused the implanted probe with an ultrapure saline solution $(0.9 \% \mathrm{NaCl}, \mathrm{pH} 7.2)$. The ultrapure saline solution is similar to blood in ionic strength and $\mathrm{pH}$ value.

The absorbance of $30 \mathrm{mg} \mathrm{1^{-1 }} \mathrm{Ca}$ standard solution was examined in terms of perfusion flow rate $(5,10,20$ and $40 \mu \mathrm{l}$ $\left.\mathrm{min}^{-1}\right)$ and sampling time $(0.5,1,1.5$ and $2 \mathrm{~min})$ using the online microdialysis-FAAS system. The results are shown in Fig. 2. The absorbance of diffusible $\mathrm{Ca}$ increases with the increase of perfusion flow rate and sampling time. However, as the perfusion flow rate increases to $40 \mu \mathrm{min}^{-1}$, the excess high perfusion flow rate may cause the mass transport resistance of $\mathrm{Ca}$ diffusion and result in a low absorbance of $\mathrm{Ca}$. As far as the rapid measurement and sufficient microdialysate volume are concerned, the $20 \mu \mathrm{min}^{-1}$ perfusion flow rate and $2 \mathrm{~min}$ of sampling time were favorable for the determination of diffusible Ca.

One of the diffusible $\mathrm{Ca}$ fractions is complex-bound $\mathrm{Ca}$ which mainly contains calcium phosphate. The phosphate would interfere with the determination of free ionized $\mathrm{Ca}$. To eliminate the chemical interference that resulted from the phosphate, La is widely used as a chemical matrix modifier. In this study, different La concentrations $(0,0.05,0.1,0.2,0.4$ in $0.5 \% \mathrm{HNO}_{3}$ ) were investigated for the determination of diffusible $\mathrm{Ca}$ in whole blood. The results showed that the highest $\mathrm{Ca}$ absorbance was observed when $0.1 \%$ La solution used.

The effect of the nebulizer uptake rate on the absorbance of diffusible $\mathrm{Ca}$ was studied by adjusting the nebulizer regulator. Figure 3 shows that the nebulizer uptake rate increases with a decrease of $\mathrm{Ca}$ absorbance (correlation coefficient $=-0.9488$ ). These results indicate that the lower the nebulizer uptake rate, the greater the absorbance that can be detected. However, unstable signals were observed at the low nebulizer uptake rate $\left(1.25 \mathrm{ml} \mathrm{min}^{-1}\right)$. In this experiment, an optimal nebulizer uptake rate of $2.5 \mathrm{ml} \mathrm{min}^{-1}$ was selected according to the analytical 


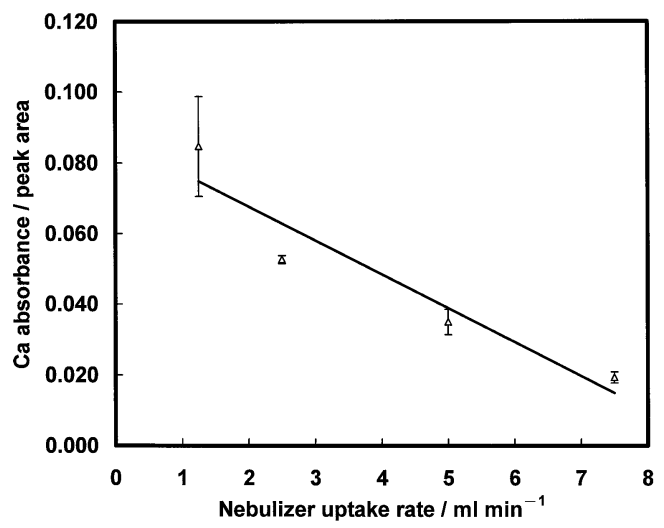

Fig. 3 Effect of the nebulizer uptake rate on the absorbance of 30 $\mathrm{mg}^{-1} \mathrm{Ca}$ standard solution using an on-line microdialysis-FAAS system. The nebulizer uptake rates of $1.25,2.5,5$ and $7.5 \mathrm{ml} \mathrm{min}^{-1}$ were coupled with different FAAS read times of 40, 20, 10 and $5 \mathrm{~s}$, respectively. The other conditions are as in Table 1 . The error bars represent standard deviations $(n=3)$.

stability and sensitivity.

Except for signal type and read time, all parameters for the determination of $\mathrm{Ca}$ using FAAS were provided from the suggested values of the instrument (Table 1). In this study, a small fixed volume of discrete microdialysate was introduced into the flame atomizer by the nebulizer uptake flow. A symmetrical or Gaussian-like signal type was formed during the process of $\mathrm{Ca}$ atomization. Therefore, the integrated peak area was evaluated as the absorbance of $\mathrm{Ca}$. Furthermore, it is important to acquire the whole atomic absorption peak within a detectable time interval. The optimized signal read time for an atomic absorption peak was $20 \mathrm{~s}$.

\section{Method validation of the on-line microdialysis-FAAS system}

The linearity of the on-line microdialysis-FAAS system was evaluated from 0 to $200 \mathrm{mg} \mathrm{l}^{-1} \mathrm{Ca}$. The calibration graph was linear in the range of 0 to $100 \mathrm{mg} \mathrm{l}^{-1}$. Ca standard solutions using the on-line system were expressed by the regression equation (zero intercept): $A=0.0015 C, r>0.9990$, where $A$ is the absorbance, $C$ the $\mathrm{Ca}$ concentration and $r$ the correlation coefficient. Above $100 \mathrm{mg} \mathrm{l}^{-1}$, the system showed a slight negative deviation from linearity. The detection limit based on three times the standard deviation of the baseline noise $(n=7)$ was $3.66 \mathrm{mg} \mathrm{l}^{-1}$.

To examine the long-term stability of the on-line microdialysis-FAAS system, the microdialysis probe was inserted into the left-ear vein of the live rabbit, followed by online sampling and detection every $2.5 \mathrm{~min}$ for $125 \mathrm{~min}(50$ continuous measurements). Figure 4 shows that all the data were in the range of average \pm 2 standard deviations. The precision of the on-line microdialysis-FAAS system for 50 measurements was $6.2 \%$ RSD.

Because no certified values for the diffusible $\mathrm{Ca}$ content in rabbit blood were available, the accuracy of the proposed online method was checked using three live rabbits and compared by employing the in vivo no net flux (NNF) method. The in vivo $\mathrm{NNF}$ is the most commonly used quantitative microdialysis method, ${ }^{23,24}$ it is based on measuring the mass transport of the analyte across the dialysis membrane as a function of the perfusate concentration. ${ }^{23}$ In the NNF method, $\mathrm{Ca}$ is added to the perfusate at concentration higher or lower than the expected true concentration. This generates a series of points that can be interpolated to determine the concentration of no net $\mathrm{Ca}$ flux,

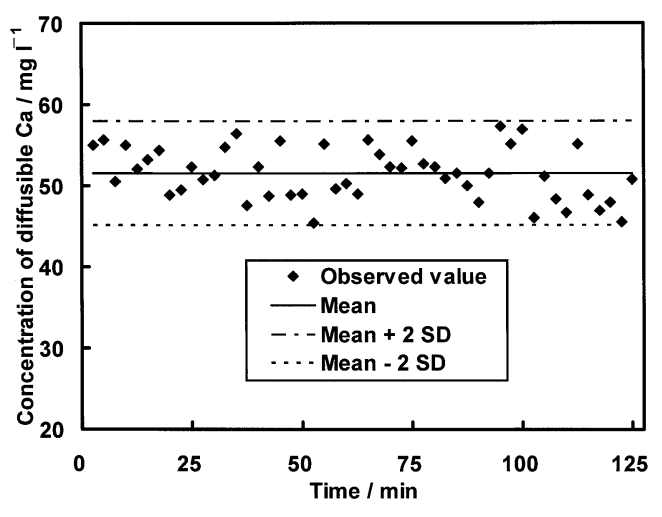

Fig. 4 Long-term stability of the proposed on-line microdialysisFAAS system using continuous on-line sampling and detection every $2.5 \mathrm{~min}$ for $125 \mathrm{~min}$ (50 continuous measurements) in the blood of living rabbits.

Table 2 Diffusible Ca concentration $\left(\mathrm{mg}^{-1}\right)$ in the blood of living rabbits as determined by the proposed on-line microdialysis-FAAS system and in vivo no net flux method (mean $\pm \mathrm{SD}, n=3$ )

\begin{tabular}{ccc}
\hline Sample & $\begin{array}{c}\text { On-line microdialysis-FAAS } \\
\text { system }\end{array}$ & $\begin{array}{c}\text { In vivo no net } \\
\text { flux method }\end{array}$ \\
\hline No. 1 rabbit & $48.3 \pm 2.6$ & $50.3 \pm 2.3$ \\
No. 2 rabbit & $49.0 \pm 2.4$ & $51.1 \pm 1.4$ \\
No. 3 rabbit & $51.7 \pm 3.1$ & $51.7 \pm 1.9$ \\
\hline
\end{tabular}

which represents the true concentration surrounding the probe. The comparisons between the on-line microdialysis-FAAS system and the in vivo NNF method are shown in Table 2 and are in good agreement within experimental error.

Overall, the favorable analytical performance of the proposed method evaluated in terms of linearity, detection limit, longterm stability and accuracy indicates that the on-line microdialysis-FAAS system is appropriate for continuous monitoring of diffusible $\mathrm{Ca}$ in the blood of living animals.

\section{In vivo study}

To demonstrate the acute distribution of $\mathrm{Ca}$ in blood, an experiment involving the intravenous injection of $\mathrm{CaCl}_{2}$ into the living rabbits was performed. Figure 5 shows the concentration profile of $\mathrm{Ca}$ in the blood of live rabbits. Basal microdialysate levels of $\mathrm{Ca}\left(53.9 \pm 4.1 \mathrm{mg} \mathrm{l}^{-1}, n=48\right)$ were determined at 2.5 min intervals for $120 \mathrm{~min}$. Twenty $\mathrm{mg} \mathrm{kg}^{-1}$ body weight of $\mathrm{CaCl}_{2}$ was intravenously injected into the right-ear vein of each rabbit. Following the administering of $\mathrm{Ca}$, the average time for the initial rise was $3.3 \pm 1.4 \mathrm{~min}(n=3)$. The average concentration of maximum $\mathrm{Ca}$ during stimulation was $101.6 \pm$ $27.3 \mathrm{mg} \mathrm{l}^{-1}(n=3)$. The average blood $\mathrm{Ca}$ concentration reached a maximum value at $5 \mathrm{~min}$ post-injection that was approximately 2 -fold higher than the basal level and the value was still higher than the base line at $120 \mathrm{~min}$ after administration with $\mathrm{CaCl}_{2}$.

\section{Conclusions}

In this work, a novel method involving on-line microdialysis sampling and FAAS detection for the in vivo monitoring of $\mathrm{Ca}$ 


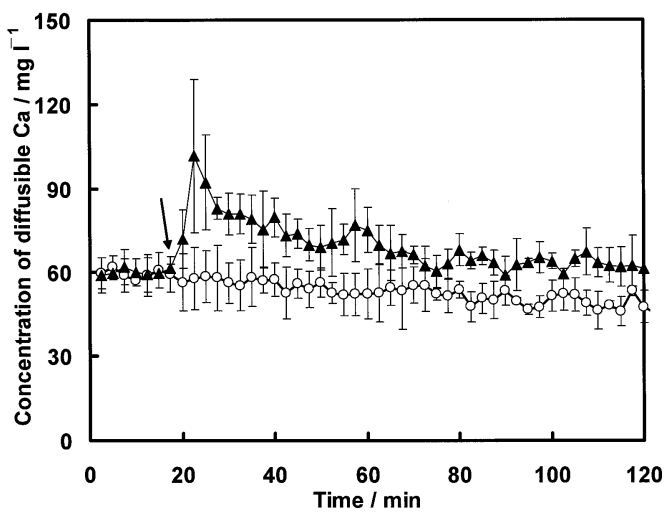

Fig. 5 The time course of Ca concentration in the blood of living rabbits following an experimental intravenous injection of $\mathrm{Ca}$. $\downarrow$, right-ear intravenous injection of $20 \mathrm{mg} \mathrm{kg}^{-1}$ body weight $\mathrm{CaCl}_{2}$ (closed triangle) or normal saline (open circle). Diffusible $\mathrm{Ca}$ in the blood of rabbits was measured using the on-line microdialysis-FAAS method. The error bars represent standard deviations $(n=3)$.

concentration in the blood of living rabbits was developed. Online microdialysis that provides direct, in situ, dynamic and continuous sampling simplifies the pretreatment of biological samples. The design of on-line microdialysis coupled with FAAS makes it possible to determine the amounts of electrolytes in living systems. The on-line system can be readily adapted to other electrolytes by varying the detection conditions of FAAS. The proposed on-line microdialysisFAAS analytical technique may also be employed advantageously to study the acute distribution of electrolytes in tissues, organs or biological fluids of living organisms.

\section{Acknowledgements}

Financial support from the National Science Council of Taiwan (NSC 91-2113-M-037-019) is gratefully acknowledged.

\section{References}

1. J. Toffaletti, Am. J. Clin. Pathol., 1995, 104, S88.

2. Y. Huang, Z. Zhang, J. Lv, and H. Cheng, Anal. Chim.
Acta, 2000, 419, 175.

3. Qi Renduo (ed.), "Diagnostics", 4th ed., 1997, The People Hygiene Press, Peking, 463.

4. R. Y. Tsien, Biochemistry, 1980, 19, 2396.

5. G. Grynkiewicz, M. Poenie, and R. Y. Tsien, J. Biol. Chem., 1985, 260, 3440.

6. R. P. Buck and V. V. Cosofret, Pure Appl. Chem., 1993, $65,1849$.

7. A. Scheipers, O. Waßmus, C. Sundermeier, J. Eshold, Th Wei $\beta$, M. Gitter, B. Roß, and M. Knoll, Anal. Chim. Acta 2001, 439, 29.

8. D. J. Weiss, C. E. Lunte, and S. M. Lunte, Trends Anal. Chem., 2000, 19, 606.

9. D. K. Hansen, M. I. Davies, S. M. Lunte, and C. E. Lunte, J. Pharm. Sci., 1999, 88, 14.

10. L. Denoroy, L. Bert, S. Parrot, F. Robert, and B. Renaud, Electrophoresis, 1998, 19, 2841.

11. M. I. Davies, Anal. Chim. Acta, 1999, 379, 227.

12. K. J. McLaughlin, A. A. Faibushevich, and C. E. Lunte, Analyst, 2000, 125, 105 .

13. J. E. Thompson, T. W. Vickroy, and R. T. Kennedy, Anal. Chem., 1999, 71, 2379.

14. F. Xiang, Y. Lin, J. Wen, D. W. Matson, and R. D. Smith, Anal. Chem., 1999, 71, 1485.

15. S. A. Wages, W. H. Church, and J. B. Justice, Anal. Chem., 1986, 58,1649

16. L. J. Deterding, K. Dix, L. T. Burka, and K. B. Tomer, Anal. Chem., 1992, 64, 1636.

17. K. M. Steele and C. E. Lunte, J. Pharm. Biomed. Anal., 1995, 13, 149.

18. Q. Fang, X-T. Shi, Y-Q. Sun, and Z. L. Fang, Anal. Chem., 1997, 69, 3570.

19. T. Yao, T. Yano, Y. Nanjyo, and H. Nishino, Anal. Sci., 2003, 19, 61

20. J. Thode, N. Fogh-Andersen, F. Aas, and O. SiggaardAndersen, Scand. J. Clin. Lab. Invest., 1985, 45, 131.

21. W. C. Tseng, M. H. Yang, T. P. Chen, and Y. L. Huang, Analyst, 2002, 127, 560.

22. W. C. Tseng, Y. C. Sun, M. H. Yang, T. P. Chen, T. H. Lin, and Y. L. Huang, J. Anal. At. Spectrom., 2003, 18, 38.

23. P. Lonnroth, P. A. Jansson, and U. Smith, Am. J. Physiol., 1987, 253, E228.

24. P. Lonnroth, P. A. Jansson, and U. Smith, J. Physiol., 1987, 256, E250. 